(C) 2021, The Authors. Published by Elsevier Inc. and Fass Inc. on behalf of the American Dairy Science Association ${ }^{\circledR}$. This is an open access article under the CC BY-NC-ND license (http://creativecommons.org/licenses/by-nc-nd/4.0/).

\title{
Short communication: Claw block application improves locomotion and weight-bearing characteristics in cattle with foot diseases
}

\author{
J. Plüss, ${ }^{*}$ () A. Steiner, $\odot$ and M. Alsaaod $(1)$ \\ Clinic for Ruminants, Vetsuisse-Faculty, University of Bern, 3001 Bern, Switzerland
}

\begin{abstract}
In cattle with foot diseases, application of a block on the healthy partner claw is a common method of pain relief. The aim of this study was to evaluate the effect of wooden claw blocks on locomotion characteristics and weight distribution in healthy (group $\mathrm{C} ; \mathrm{n}=17$ ) versus lame (group $\mathrm{L} ; \mathrm{n}=17$ ) cattle. Group $\mathrm{L}$ was further subdivided into group L1 (lameness score $\leq 3$; $\mathrm{n}=7$ ) and group L2 (lameness score $>3 ; \mathrm{n}=10$ ). We performed lameness scoring using a numeric rating system and measured locomotion characteristics using 2 accelerometers $(400 \mathrm{~Hz}$; kinematic outcome $=$ stance phase duration; kinetic outcomes $=$ foot load and toeoff) and a 4-scale weighing platform (difference of mean weight distribution across the limbs; $\Delta_{\text {weight }}$ ) before and after application of a claw block. We applied claw blocks to a randomly assigned lateral or medial claw of the fore or hindlimb in group C cows, and on the healthy partner claw in group L cows. Variables were expressed as differences across limbs. We used 1-way ANOVA to determine the differences between groups $\mathrm{C}$ and $\mathrm{L}$ and between groups L1 and L2 for $\Delta_{\text {weight }}$ after application of the claw block. We performed paired t tests to compare variables before and after application of the claw block in groups $\mathrm{C}$ and L. Group L scored higher on the numeric rating system than group $\mathrm{C}$ (mean $\pm \mathrm{SD}, 3.40$ \pm 0.62 vs. $1.87 \pm 0.28$ ) and showed greater differences in relative stance phase duration $(16.34 \pm 10.78 \%$ vs. $2.13 \pm 1.94 \%)$, foot load $(9.68 \pm 8.06 \mathrm{~g}$ vs. $3.26 \pm 3.69$ $g)$, toe-off $(3.91 \pm 3.14 \mathrm{~g}$ vs. $0.78 \pm 0.66 \mathrm{~g})$, and $\Delta_{\text {weight }}$ $(53.62 \pm 28.85 \%$ vs. $8.52 \pm 6.19 \%)$. In group C, we observed an increase of 12.17 percentage points in $\Delta_{\text {weight }}$ after block application, from $8.52 \pm 6.19 \%$ to $20.69 \pm$ $17.01 \%$. Compared with the baseline, group L showed a decrease in numeric rating system score $(2.88 \pm 0.49$ vs. $3.40 \pm 0.62)$ and a decrease in differences between the limbs in relative stance phase duration $(7.66 \pm 9.96 \%$ vs. $16.34 \pm 10.78 \%)$ and foot load $(4.26 \pm 4.14 \mathrm{~g}$ vs.
\end{abstract}

Received June 22, 2020.

Accepted September 27, 2020.

*Corresponding author: janet.pluess@bluewin.ch
$9.68 \pm 8.06 \mathrm{~g})$ after application of a claw block. Group L2 showed smaller $\Delta_{\text {weight }}$ after application of a claw block than group L1 $(-7.8 \pm 8.7 \%$ vs. $10.4 \pm 7.6 \%)$. After block application in group L, we observed smaller differences across the limbs in variables measured to describe gait-cycle characteristics while walking, but no significant improvement while standing. We concluded that application of a claw block must be combined with other methods of pain relief, such as analgesic medication.

Key words: cattle, lameness, gait cycle, weightbearing, claw block

\section{Short Communication}

Lameness in cattle is a major welfare issue, because it is often associated with severe pain in the lower limb (O'Callaghan, 2002) and long-lasting increased sensitivity of the affected claw (Whay et al., 1998). Early detection and treatment play a crucial role in the successful prevention and treatment of lameness (Leach et al., 2012), because the rate of recovery after treatment is lower in cows with chronic foot diseases (Thomas et al., 2016). The prevalence of lameness in cattle has been reported to be $31.6 \%$ in the United Kingdom (Griffiths et al., 2018), 31\% in China (Chapinal et al., 2014), 17.2 to $30.5 \%$ in the United States (Salfer et al., 2018), $21 \%$ in Finland (Sarjokari et al., 2013), 15 to 21\% in Canada (Jewell et al., 2019), 16\% in Brazil (Moreira et al., 2018), 14.8\% in Switzerland (Becker et al., 2014), and $8.1 \%$ in New Zealand (Fabian et al., 2014). Options for treatment and pain management in cattle affected by foot diseases include claw-trimming (Shearer and van Amstel, 2001), analgesia with nonsteroidal anti-inflammatory drugs (NSAID; Whay et al., 2005; Wagner et al., 2017; Alsaaod et al., 2019), and applying a block to the sound partner claw of the affected limb (Toussaint Raven, 1989; Pyman, 1997). To eliminate the underlying cause of pain, corrective claw-trimming is often performed, in combination with surgical debridement (Laven et al., 2008; Thomas et al., 2015). For acutely lame cows, combined therapy consisting of trimming, NSAID, and wooden block application showed promis- 
Table 1. Foot diseases and associated numeric rating system (NRS) score before block application in cattle of the lame group $(\mathrm{n}=17)^{1,2}$

\begin{tabular}{lll}
\hline Animal & Foot disease & NRS \\
\hline 1 & Sole hemorrhage, white line abscess, osteitis of the pedal bone & 2.75 \\
2 & Sole hemorrhage, double sole, white line abscess & 3 \\
3 & Toe necrosis, osteitis of the pedal bone & 3.5 \\
4 & Toe necrosis, osteitis of the pedal bone & 3.5 \\
5 & Sole ulcer, septic arthritis of the distal interphalangeal joint & 2.75 \\
6 & Osteoarthritis of the distal interphalangeal joint, osteoarthritis of the proximal interphalangeal joint \\
7 & Fracture of the pedal bone & 4 \\
8 & Sole hemorrhage, osteitis of the pedal bone & \\
9 & Toe necrosis, osteitis of the pedal bone, fracture of the pedal bone & \\
10 & White line abscess & \\
11 & White line abscess & 3.7 \\
12 & Osteitis of the pedal bone, osteitis of the os sesamoideum distale & \\
13 & Septic tendovaginitis of the common digital flexor tendon sheath & \\
14 & Toe necrosis & 3 \\
15 & Septic tendovaginitis of the common digital flexor tendon sheath \\
16 & Sole ulcer, septic arthritis of the distal interphalangeal joint & 3.75 \\
17 & Sole ulcer, septic arthritis of the distal interphalangeal joint & 4.5 \\
\hline
\end{tabular}

${ }^{1}$ NRS $=$ numeric rating system, according to Flower and Weary (2006), calculated as the mean rating of 2 independent trained veterinary specialists.

${ }^{2}$ The diagnosed foot disease(s) of every animal is listed separately.

ing results in curing lameness in a study by Thomas et al. (2015). Even though the application of a claw block is a well-known treatment option in lame cattle, little information is available about its effect on locomotion characteristics and weight distribution. Validated tools for the objective evaluation of locomotion represent a promising approach for detecting foot diseases in cattle (Beer et al., 2016; Nechanitzky et al., 2016; Alsaaod et al., 2017a). The objective of this study was to measure and compare the effect of temporary wooden claw blocks on locomotion characteristics and weight distribution in healthy and lame cattle.

The protocol for the present study was approved by the animal experimentation committee of the canton of Berne, Switzerland (permission \#30150). Data were collected from 2 independent groups of cows at 2 different locations. The control group (group C) consisted of 17 dairy cows from the farm of an agricultural school (Inforama Rütti, Zollikofen, Switzerland) with a lameness score $<3$ using a 5 -point numeric rating system (NRS; $1=$ non-lame and $5=$ severely lame) from Flower and Weary (2006), and no clinical signs of any foot disorder. If an animal exceeded the traits of a particular NRS score but did not meet all of the score's criteria, we used half-integer scores (Flower and Weary, 2006). The lame group (group L) included 17 cattle that had been referred to the Clinic for Ruminants, Vetsuisse-Faculty, University of Bern, with a foot disease in 1 affected front $(\mathrm{n}=4)$ or hind limb $(\mathrm{n}=13)$ with only 1 digit affected. No NSAID were administered on the measuring day. In cattle that received analgesic medication before admission to the clinic in group L, more than 4.5 times the elimination half-life of the medication had passed. The animals underwent thorough general clinical, orthopedic, ultrasonographic, or radiographic examination if indicated (Dirksen et al., 2012). Foot diseases were described according to the guidelines of the ICAR Claw Health Atlas (www.icar.org/ICAR _Claw_Health_Atlas.pdf) and Nuss et al. (2019). All diagnosed foot diseases are listed in Table 1. We used a scale of 1 (thin) to 5 (obese) with a quarter-point system to estimate BCS (Edmonson et al., 1989).

Cattle in group $\mathrm{C}$ had an age (mean \pm standard deviation) of $57.24 \pm 22.98 \mathrm{mo}$, a BCS of $3.27 \pm 0.32$, and a BW of $701.35 \pm 98.93 \mathrm{~kg}$. Two cows were dry, and the other cows had a milk yield of $22.75 \pm 8.29 \mathrm{~L}$. Breeds in group C were Red Holstein $(\mathrm{n}=11)$, Swiss Fleckvieh ( $\mathrm{n}$ $=5)$, and Holstein -Friesian $(\mathrm{n}=1)$. Cattle in group $\mathrm{L}$ had an age of $64.47 \pm 35.13 \mathrm{mo}$, a BCS of $2.89 \pm 0.44$, and a BW of $596.18 \pm 98.12 \mathrm{~kg}$. One heifer had not yet been inseminated, and 4 cows were dry; the other cows had a milk yield of $29.92 \pm 8.26 \mathrm{~L}$. Breeds in group L were Red Holstein $(\mathrm{n}=4)$, Holstein-Friesian $(\mathrm{n}=4)$, Swiss Fleckvieh $(\mathrm{n}=3)$, Simmental $(\mathrm{n}=2)$, Brown Swiss $(\mathrm{n}=2)$, and Eringer $(\mathrm{n}=2)$.

In a claw-trimming chute, a wooden claw blocksmall $(11 \times 5.2 \times 2.1 \mathrm{~cm})$ or large $(12.6 \times 5.8 \times 2.5$ $\mathrm{cm})$, depending on the size of the claw-was temporarily applied to a randomly assigned lateral or medial claw of the fore or hind limb using adhesive tape (without touching the skin) in group C. In group L, the block was glued with a polyurethane adhesive (Technovit-2-Bond; Kulzer GmbH, Wehrheim, Germany) to the claw of the healthy partner digit. After the claw block was applied, the animals were walked $20 \mathrm{~m}$ to adapt to the blocks. Cattle were given 5 to $10 \mathrm{~min}$ to get used to standing 
quietly on the weighing platform. Measurement was started manually when they were standing with each limb positioned on the appropriate unit. Measurements of locomotion characteristics and weight distribution were taken before and after application of the claw block.

We used a digital video camera (50 frames/s; Sony HDR-PJ740VE; Sony Corporation, Tokyo, Japan) to record every cow as it walked on an asphalt floor in a straight line for $20 \mathrm{~m}$. Each cow's gait was scored by 2 experienced observers (at least 1 year of experience locomotion scoring in cattle; JP and MA), independent of each other. To maximize the reliability of the locomotion scoring, the mean value of the video analysis of 2 observers was calculated and used for further statistical analysis. Cows with a mean NRS score $\geq 3$ were classified as lame. For further analysis, we subdivided group L into 2 groups: L1 (NRS score $\leq 3 ; \mathrm{n}=7$ ) and L2 (NRS score $>3 ; \mathrm{n}=10$ ).

Gait cycle variables of the cow pedogram were measured using 2 standalone 3 -dimensional accelerometers (400 Hz; USB-Accelerometer X16-4; Gulf Coast Data Concepts, Waveland, MS) after video recording for NRS score. The accelerometers were fitted at the level of both metatarsi or both metacarpi (depending on the location of the foot disease) in group L, or at the location of the randomly assigned claw block in group C. Each animal was encouraged by a trained animal caretaker to walk in a straight line for a distance of 10 $\mathrm{m}$ or more on an asphalt floor, guided with a halter. We selected a mean of 9.4 gait cycles (range $5-15$ ) per limb pair for convenience after excluding gait cycles that represented running or had signal artifacts (as determined by visual inspection). Using a validated semiautomated software tool called Cow-Gait-Analyzer, we displayed the pedogram and analyzed various gait-cycle variables, as described by Alsaaod et al. (2017a,b). The gait-cycle variables consisted of temporal events of kinematic outcomes [relative stance phase duration (percentage of time the claw was in contact with the ground relative to the duration of the total gait cycle)] and peaks of kinetic outcomes [foot load (maximum acceleration of the initial ground contact of the claw; gravity force, $g$ ) and toe-off (maximum acceleration of the termination of the ground contact of the tip of the claw; $g)$.

Weight distribution across contralateral limbs was measured as described by Nechanitzky et al. (2016), using a 4-scale weighing platform $(1.94 \times 1.06 \mathrm{~m}$; ITIN+HOCH GmbH, Fütterungstechnik, Liestal, Switzerland), consisting of 4 recording units $(0.78 \times$ $0.55 \mathrm{~m}$ ) that all contained one hermetically sealed load cell (Hottinger Baldwin Messtechnik AG, Volketswil, Switzerland) covered with individual rubber mats 10 mm thick. Data were continuously recorded at $10 \mathrm{~Hz}$, and data acquisition was automatically stopped when the measured total weight on all 4 platforms showed a deviation of more than $5 \%$ from the initially obtained BW. Measurement was restarted manually when the cow stood in an adequate position again. We calculated the mean weight from 5 min of data acquisition for each limb and used this for further analysis (Nechanitzky et al., 2016).

The 3 researchers (JP, AS, and MA) were blinded as to the source of the data, and analysis was performed at cow level. Gait cycle variables were calculated as the absolute difference across the contralateral limbs of the examined limb pair, and weight distribution as the percent absolute difference of the mean weight across the examined limbs $\left(\boldsymbol{\Delta}_{\text {weight }}\right)$. Statistical analyses were performed using the statistics package NCSS (NCSS LLC, Kaysville, UT; www.ncss.com/). The normality of all analyzed variables was checked using the ShapiroWilk test (normality as $>0.95$ ). A one-way ANOVA was used to determine the differences between groups $\mathrm{C}$ and L for NRS score, relative stance phase, foot load, toe-off, and $\Delta_{\text {weight }}$, and for cows in group L1 versus L2 for $\Delta_{\text {weight }}$ after application of the claw block. We also used ANOVA to determine the difference between groups L1 and L2 for $\Delta_{\text {weight }}$ after application of the claw block, and performed a post hoc power calculation using G*Power version 3.1.9.2 (www.gpower.hhu.de/). The values for $\alpha$ and sample size were set at 0.05 and 17 cows, respectively. The actual values for differences in the means ( \pm standard deviation) of $\Delta_{\text {weight }}$ in groups L1 and L2 were used to calculate power. We performed a paired-sample $t$-test to compare the differences in NRS score, relative stance phase, foot load, toe-off, and $\Delta_{\text {weight }}$ before and after claw block application in groups $\mathrm{C}$ and $\mathrm{L}$, respectively.

Results for the comparison of NRS score, gait-cycle variables, and weight-distribution variables in group $\mathrm{C}$ versus group L are given in Table 2. Group L had a significantly higher NRS score $(P<0.001)$, and we observed significantly higher differences across the limbs for all gait-cycle variables $(P<0.001)$ and a significantly higher $\Delta_{\text {weight }}(P<0.001)$ in group L compared with group C.

Results for the comparison of NRS score, gait-cycle variables, and weight-distribution variables before and after application of the claw block in each group are also given in Table 2. In group $\mathrm{C}$, we found no significant differences in NRS score or gait-cycle variables before versus after application of the claw block, but $\Delta_{\text {weight }}$ increased significantly after claw block application $(P=0.023)$ compared with the measurements without claw blocks. We found an increase in weight on the limbs with blocks compared with the corresponding 
limbs without blocks in 5 cows $(12.51 \pm 11.47 \mathrm{~kg})$ and a decrease in 12 cows $(-39.02 \pm 29.28 \mathrm{~kg})$. Group L had significantly lower NRS scores $(P<0.001)$, significantly reduced differences in the gait-cycle variables of relative stance phase duration $(P=0.025)$ and foot load $(P=$ $0.023)$, and a tendency to a reduced difference across the limbs in toe-off $(P=0.057)$ after application of the claw block compared with the measurements without claw blocks. However, the difference in $\Delta_{\text {weight }}$ was not significant in group L $(P=0.89)$. Group L2 showed a significantly lower $\Delta_{\text {weight }}$ after application of the claw block than group L1 (mean \pm standard deviation; -7.8 \pm 8.7 vs. $10.4 \pm 7.6 ; P=0.005$; power $=0.99$ ).

The application of a block to the healthy partner claw is a commonly used procedure known worldwide for pain relief and treatment of various claw disorders in cattle (Toussaint Raven, 1989; Pyman, 1997; Thomas et al., 2015). However, to the best of our knowledge, this is the first report of combined measurements of NRS score, gait-cycle variables, and weight-bearing variables to determine the effect of wooden claw blocks in healthy and lame cattle. Combining the NRS score as a subjective description of locomotion with the objective data of the cow pedogram and the weighing platform allowed for a thorough assessment of locomotion in cattle. Group L scored higher on the NRS than group $\mathrm{C}$, in agreement with previous studies, in which lameness is described as an indicator for, or sign of, pain associated with claw disorders (Whay et al., 1998; O'Callaghan, 2002; Flower and Weary, 2006). The differences across limbs in gait-cycle variables and weight distribution were higher in group L than in group C. This agreed with previous results, in which the differences between the limbs in kinetic (foot load, toe-off) and kinematic (relative stance phase) variables on the cow pedogram, as well as the difference between the limbs in $\Delta_{\text {weight, }}$, were significantly greater in lame cows than in non-lame cows, showing the usefulness of objective methods of lameness detection in cattle (Nechanitzky et al., 2016; Alsaaod et al., 2017a,b; Buisman et al., 2018).

After application of the claw block, NRS score and cow pedogram findings did not differ significantly for group C. In contrast, Cutler et al. (2015) found a significant increase in locomotion scores in healthy cows on d 1 to 3 after application of wooden blocks. This difference might be explained by the fact that we observed the short-term effect of wooden blocks on the locomotion characteristics of cattle, whereas Cutler et al. (2015) did not perform measurements on the day of block application. In group C, $\Delta_{\text {weight }}$ increased significantly after application of the claw block. An explanation for this finding could be that the cows were not familiar with the physical elevation of 1 digit, leading to an increase of the length of the limb. In group L, the NRS decreased after application of the claw block. This finding agreed with the results of Pyman (1997), who investigated lameness in dairy cattle and found a significantly higher proportion of cows with foot diseases were only slightly lame or showed no lameness on d 3 and 7 after applying a wooden block or a rubber shoe compared to cows who were treated with padded bandages. Similar to the NRS score, differences across limbs for relative stance phase duration and peak of foot load were significantly lower after application of the claw block. Thus, the objective results of the cow pedogram affirmed the subjective results of the NRS score; they both suggested a reduced expression of pain while walking. We found no change in $\Delta_{\text {weight }}$ in group $\mathrm{L}$ after application of the claw block. This might have been a sign that weight difference across the limbs during standing was a less sensitive measurement for the

Table 2. Numeric rating system (NRS) scores and differences in gait cycle variables and weight distribution in each group (mean $\pm \mathrm{SD}$ ) before and after application of a claw block ${ }^{1,2}$

\begin{tabular}{lccccc}
\hline & \multicolumn{2}{c}{ Group C (control; healthy) } & & \multicolumn{2}{c}{ Group L (lame) } \\
\cline { 2 - 3 } \cline { 5 - 6 } Variable & Before block & After block & & Before block & After block \\
\hline NRS & $1.87 \pm 0.28^{\mathrm{a}}$ & $1.93 \pm 0.36$ & & $3.40 \pm 0.62^{\mathrm{b}, \mathrm{A}}$ & $2.88 \pm 0.49^{\mathrm{B}}$ \\
Stance phase $(\%)$ & $2.13 \pm 1.94^{\mathrm{a}}$ & $2.87 \pm 1.94$ & & $16.34 \pm 10.7^{\mathrm{b}, \mathrm{A}}$ & $7.66 \pm 9.96^{\mathrm{B}}$ \\
Foot load $(g)$ & $3.26 \pm 3.69^{\mathrm{a}}$ & $4.23 \pm 3.13$ & & $9.68 \pm 8.06^{\mathrm{b}, \mathrm{A}}$ & $4.26 \pm 4.14^{\mathrm{B}}$ \\
Toe-off $(g)$ & $0.78 \pm 0.66^{\mathrm{a}}$ & $0.99 \pm 1.07$ & & $3.91 \pm 3.14^{\mathrm{b}}$ & $2.28 \pm 1.27$ \\
$\Delta_{\text {weight }}(\%)$ & $8.52 \pm 6.19^{\mathrm{a}, \mathrm{A}}$ & $20.69 \pm 17.01^{\mathrm{B}}$ & & $53.62 \pm 28.85^{\mathrm{b}}$ & $53.11 \pm 25.89$ \\
\hline
\end{tabular}

${ }^{\mathrm{a}, \mathrm{b}}$ Means within a row with different lowercase superscript letters differed significantly between groups before block application $(P \leq 0.05)$.

${ }_{\mathrm{A}, \mathrm{B}}$ Means within a row with different uppercase superscript letters differed significantly within groups before and after block application $(P \leq 0.05)$.

${ }^{1}$ NRS according to Flower and Weary (2006), calculated as the mean rating of 2 independent trained veterinary specialists; $\Delta_{\text {weight }}=$ difference in weight distribution.

${ }^{2}$ Gait cycle variables were calculated as the absolute difference across the contralateral limbs; $\Delta_{\text {weight }}$ was calculated as the percent absolute difference of the mean weight across the contralateral limbs. 
detection of pain relief than kinematic variables during walking. Rushen et al. (2007) found greater variability in the weight applied to the injured leg and the contralateral leg in lame cows compared to non-lame cows. Another explanation could be dissimilar weight-bearing during walking versus standing. When standing, cows have the natural opportunity to shift weight between limb pairs and can therefore reduce weight-bearing on the affected limb. In locomotion, cows are forced to put a certain amount of weight on a painful limb, making pain relief by block application such an important tool. For further calculations, we subdivided group L into groups L1 (NRS score $\leq 3 ; \mathrm{n}=7$ ) and L2 (NRS score $>3, \mathrm{n}=10$ ). Cows in group L2 showed a significantly smaller difference in $\Delta_{\text {weight }}$ after application of the claw block than cows in group L1. This again underlines the usefulness of the application of claw blocks in treating lame cattle and emphasizes the potential and importance of additional treatment modalities, because lameness is an important issue in animal welfare (Whay and Shearer, 2017). We used 2 sizes of claw blocks (according to the size of the respective claws) with a difference of $0.4 \mathrm{~cm}$ in height, which could have influenced locomotion characteristics in the respective animals and would provide an interesting question for further research. Analgesic medication is a useful tool for treating lameness in cattle, and a previous study determined the short-term effect of ketoprofen for improving differences across limbs when walking and standing (Alsaaod et al., 2019). Furthermore, in cows with claw horn lesions, the combination of NSAID with therapeutic claw-trimming and a claw block led to a significantly higher proportion of cows recovering from lameness than treatment with foot-trimming alone, or foot-trimming combined with either a claw block or NSAID administration (Thomas et al., 2015).

We observed smaller differences in variables measured during walking in lame cattle, but no significant differences in variables representing pain relief when standing after the application of wooden claw blocks. Claw block application should not be used as the only tool for pain relief and support of healing in cattle with foot disease in a single affected limb. Based on our results and on those of our previous study (Alsaaod et al., 2019), we recommend that claw blocks be used in combination with other methods of pain relief, such as analgesic medication.

\section{ACKNOWLEDGMENTS}

We thank Damian Iten and Annina Müller (Clinic for Ruminants, Vetsuisse-Faculty, University of Bern, Switzerland) for their help with data collection, Thomas
Oberli (Clinic for Ruminants, Vetsuisse-Faculty, University of Bern) for his assistance with animal handling, and the employees of both the agricultural school Inforama Rütti and the Clinic for Ruminants, University of Bern, for their cooperation. The authors have not stated any conflicts of interest.

\section{REFERENCES}

Alsaaod, M., M. Fadul, R. Deiss, E. Bucher, J. Rehage, J. Guccione, and A. Steiner. 2019. Use of validated objective methods of locomotion characteristics and weight distribution for evaluating the efficacy of ketoprofen for alleviating pain in cows with limb pathologies. PLoS One 14:e0218546. https://doi.org/10.1371/journal .pone.0218546.

Alsaaod, M., R. Kredel, B. Hofer, and A. Steiner. 2017b. Technical note: Validation of a semi-automated software tool to determine gait-cycle variables in dairy cows. J. Dairy Sci. 100:4897-4902. https://doi.org/10.3168/jds.2016-12235.

Alsaaod, M., M. Luternauer, T. Hausegger, R. Kredel, and A. Steiner. 2017a. The cow pedogram - analysis of gait cycle variables allows the detection of lameness and foot pathologies. J. Dairy Sci. 100:1417-1426. https://doi.org/10.3168/jds.2016-11678.

Becker, J., A. Steiner, S. Kohler, A. Koller-Bähler, M. Wüthrich, and M. Reist. 2014. Lameness and foot lesions in Swiss dairy cows: I. Prevalence. Schweiz. Arch. Tierheilkd. 156:71-78. https://doi.org/ 10.1024/0036-7281/a000553.

Beer, G., M. Alsaaod, A. Starke, G. Schuepbach-Regula, H. Müller, P. Kohler, and A. Steiner. 2016. Use of extended characteristics of locomotion and feeding behavior for automated identification of lame dairy cows. PLoS One 11:e0155796. https://doi.org/10.1371/ journal.pone.0155796.

Buisman, L. L., M. Alsaaod, E. Bucher, J. Kofler, and A. Steiner. 2018. Objective assessment of lameness in cattle after foot surgery. PLoS One 13:e0209783. https://doi.org/10.1371/journal.pone.0209783.

Chapinal, N., Y. Liang, D. M. Weary, Y. Wang, and M. A. von Keyserlingk. 2014. Risk factors for lameness and hock injuries in Holstein herds in China. J. Dairy Sci. 97:4309-4316. https://doi.org/ $10.3168 /$ jds.2014-8089.

Cutler, J. H., J. K. Shearer, D. F. Kelton, G. Cramer, P. J. Gorden, and S. T. Millman. 2015. An observational study of the effects of therapeutic hoof blocks on the locomotion, behaviour, and production of healthy dairy cattle. J. Appl. Anim. Welf. Sci. 18:363-374. https://doi.org/10.1080/10888705.2015.1033626.

Dirksen, G., H. D. Gründer, and M. Stöber. 2012. Die Klinische Untersuchung des Rindes. 4th ed. Enke Verlag, Stuttgart, Germany. [In German]

Edmonson, A., I. Lean, L. Weaver, T. Farver, and G. Webster. 1989. A body condition scoring chart for Holstein dairy cows. J. Dairy Sci. 72:68-78. https://doi.org/10.3168/jds.S0022-0302(89)79081-0.

Fabian, J., R. A. Laven, and H. R. Whay. 2014. The prevalence of lameness on New Zealand dairy farms: A comparison of farmer estimates and locomotion scoring. Vet. J. 201:31-38. https://doi .org/10.1016/j.tvj1.2014.05.011.

Flower, F. C., and D. M. Weary. 2006. Effect of hoof pathologies on subjective assessments of dairy cow gait. J. Dairy Sci. 89:139-146. https://doi.org/10.3168/jds.S0022-0302(06)72077-X.

Griffiths, B. E., D. Grove White, and G. Oikonomou. 2018. A crosssectional study into the prevalence of dairy cattle lameness and associated herd-level risk factors in England and Wales. Front. Vet. Sci. 5:65. https://doi.org/10.3389/fvets.2018.00065.

Jewell, M. T., M. Cameron, J. Spears, S. L. McKenna, M. S. Cockram, J. Sanchez, and G. P. Keefe. 2019. Prevalence of lameness and associated risk factors on dairy farms in the Maritime provinces of Canada. J. Dairy Sci. 102:3392-3405. https://doi.org/10.3168/jds .2018-15349.

Laven, R. A., K. E. Lawrence, J. F. Weston, K. R. Dowson, and K. J. Stafford. 2008. Assessment of the duration of the pain response 
associated with lameness in dairy cows, and the influence of treatment. N. Z. Vet. J. 56:210-217. https://doi.org/10.1080/00480169 .2008 .36835 .

Leach, K. A., D. A. Tisdall, N. J. Bell, D. C. J. Main, and L. E. Green. 2012. The effects of early treatment for hindlimb lameness in dairy cows on four commercial UK farms. Vet. J. 193:626-632. https:// doi.org/10.1016/j.tvjl.2012.06.043.

Moreira, T. F., R. R. Nicolino, L. S. de Andrade, E. J. F. Filho, and A. U. de Carvalho. 2018. Prevalence of lameness and hoof lesions in all year-round grazing cattle in Brazil. Trop. Anim. Health Prod. 50:1829-1834. https://doi.org/10.1007/s11250-018-1626-3.

Nechanitzky, K., A. Starke, B. Vidondo, H. Müller, M. Reckardt, K. Friedli, and A. Steiner. 2016. Analysis of behavioral changes in dairy cows associated with claw horn lesions. J. Dairy Sci. 99:2904-2914. https://doi.org/10.3168/jds.2015-10109.

Nuss, K., J. Kofler, A. Fiedler, and A. Steiner. 2019. Spezielle Diagnostik und Therapie. Pages 102-163 in Erkrankungen der Klauen und Zehen des Rindes. 2nd ed. A. Fiedler, J. Maierl, and K. Nuss, ed. Georg Thieme Verlag, Stuttgart, Germany. [In German]

O'Callaghan, K. 2002. Lameness and associated pain in cattle: Challenging traditional perceptions. In Pract. 24:212-219. https://doi .org/10.1136/inpract.24.4.212.

Pyman, M. F. 1997. Comparison of bandaging and elevation of the claw for the treatment of foot lameness in dairy cows. Aust. Vet. J. 75:132-135. https://doi.org/10.1111/j.1751-0813.1997.tb14173.x.

Rushen, J., E. Pombourcq, and A. M. de Passillé. 2007. Validation of two measures of lameness in dairy cows. Appl. Anim. Behav. Sci. 106:173-177. https://doi.org/10.1016/j.applanim.2006.07.001.

Salfer, J. A., J. M. Siewert, and M. I. Endres. 2018. Housing, management characteristics, and factors associated with lameness, hock lesion, and hygiene of lactating dairy cattle on Upper Midwest United States dairy farms using automatic milking systems. J. Dairy Sci. 101:8586-8594. https://doi.org/10.3168/jds.2017-13925.

Sarjokari, K., K. O. Kaustell, T. Hurme, T. Kivinen, O. A. T. Peltoniemi, H. Saloniemi, and P. J. Rajala-Schultz. 2013. Prevalence and risk factors for lameness in insulated free stall barns in Finland. Livest. Sci. 156:44-52. https://doi.org/10.1016/j.livsci.2013.06 .010 .
Shearer, J. K., and S. R. van Amstel. 2001. Functional and corrective claw trimming. Vet. Clin. North Am. Food Anim. Pract. 17:53-72. https://doi.org/10.1016/S0749-0720(15)30054-2.

Thomas, H. J., G. G. Miguel-Pacheco, N. J. Bollard, S. C. Archer, N. J. Bell, C. Mason, O. J. R. Maxwell, J. G. Remnant, P. Sleeman, H. R. Whay, and J. N. Huxley. 2015. Evaluation of treatments for claw horn lesions in dairy cows in a randomized controlled trial. J. Dairy Sci. 98:4477-4486. https://doi.org/10.3168/jds.2014-8982.

Thomas, H. J., J. G. Remnant, N. J. Bollard, A. Burrows, H. R. Whay, N. J. Bell, C. Mason, and J. N. Huxley. 2016. Recovery of chronically lame dairy cows following treatment for claw horn lesions: A randomised controlled trial. Vet. Rec. 178:116. https://doi.org/10 $.1136 /$ vr.103394.

Toussaint Raven, E. 1989. Cattle Footcare and Claw Trimming. Farming Press, Ipswich, UK.

Wagner, S. A., J. M. Young, J. K. Tena, and B. H. Manning. 2017. Short communication: Behavioral evaluation of the analgesic effect of flunixin meglumine in lame dairy cows. J. Dairy Sci. 100:65626566. https://doi.org/10.3168/jds.2016-12331.

Whay, H. R., and J. K. Shearer. 2017. The impact of lameness on welfare of the dairy cow. Vet. Clin. North Am. Food Anim. Pract. 33:153-164. https://doi.org/10.1016/j.cvfa.2017.02.008.

Whay, H. R., A. E. Waterman, A. J. F. Webster, and J. K. O'Brien. 1998. The influence of lesion type on the duration of hyperalgesia associated with hindlimb lameness in dairy cattle. Vet. J. 156:2329. https://doi.org/10.1016/S1090-0233(98)80058-0.

Whay, H. R., A. J. F. Webster, and A. E. Waterman-Pearson. 2005. Role of ketoprofen in the modulation of hyperalgesia associated with lameness in dairy cattle. Vet. Rec. 157:729-733. https://doi .org/10.1136/vr.157.23.729.

\section{ORCIDS}

J. Plüss () https://orcid.org/0000-0002-2445-3341

A. Steiner @ https://orcid.org/0000-0003-2415-3768

M. Alsaaod ( https://orcid.org/0000-0003-0686-7118 